\title{
LEGISLAÇÃO BRASILEIRA SOBRE CURSOS STRICTO SENSU REALIZADOS FORA DO BRASIL E A VISÃO DO MEC
}

\section{ARTIGO DE REVISÃO}

BABY, Girley Bueno ${ }^{1}$

MENDES, Celeste ${ }^{2}$

PEREIRA, Paulo Roberto Barbosa ${ }^{3}$

BABY, Girley Bueno. MENDES, Celeste. PEREIRA, Paulo Roberto Barbosa. Legislação brasileira sobre cursos Stricto Sensu realizados fora do Brasil e a visão do MEC. Revista Científica Multidisciplinar Núcleo do Conhecimento. Ano 04, Ed. 12, Vol. 04, pp. 191-208 . Dezembro de 2019. ISSN: 2448-0959, Link de acesso: https://www.nucleodoconhecimento.com.br/educacao/legislacao-brasileira

\section{RESUMO}

O principal objeto de estudo deste artigo é levantar informações sobre o contexto legislativo, regulatório e instrucional brasileiro sobre os cursos stricto sensu realizados no exterior, a intervenção, ações de responsabilidade do Ministério da Educação e Cultura/MEC e da Coordenação de Aperfeiçoamento de Pessoal de Nível Superior (CAPES). Justifica-se a presente pesquisa, que por força de necessidades emergentes, provocaram iniciativas do Ministério da Educação e Cultura/MEC, intervindo na atualização de instrumentos legais de amparo aos cursos stricto sensu sob a égide de grande demanda desta modalidade de especialização. Destaca-se a

\footnotetext{
${ }^{1}$ Mestrando em Ciências da Educação; Pós-Graduado em Educação Física Escolar; Bacharel em Educação Física.

2 Doutora em Ciências da Educação.

${ }^{3}$ Doutorado em Ciências da Educação. Doutorado em Ciências da Educação. Especialização em Supervisão Escolar. Graduação em Pedagogia.
} 
estrutura da sistematização dos programas dos cursos stricto sensu que se caracterizam em mestrado acadêmico e profissional e doutorado amparados pela lei brasileira, podendo ser realizados em instituições de ensino de outros países, por meio de acordos específicos - como no caso do Mercosul - contudo, todo e qualquer título obtido em qualquer outro país, está sujeito à revalidação por instituição de ensino superior brasileira conforme a Lei de Diretrizes e Bases da Educação-LDB/1996 e demais leis e resoluções complementares. O processo se torna um tanto quanto burocrático e nem sempre assegura que o indivíduo que obteve o título de mestre e doutor no exterior, conseguirá usufruir dos benefícios desse título em seu próprio país. Utilizou-se o método da pesquisa bibliográfica em caráter qualitativo baseados em artigos acadêmicos, revistas eletrônicas, legislação específica do Ministério da Educação e outras fontes de exclusiva ao tema proposto.

Palavras-Chave: Legislação, MEC/CAPES, mestrado, pós-graduação, Stricto Sensu.

\section{INTRODUÇÃO}

A história da pós-graduação no Brasil, como atividade acadêmica constituída de programas, cursos, disciplinas, regulamentações, é um fenômeno datado da segunda metade do século XX. Os Estados Unidos foram pioneiros na organização desses cursos, o que advém tanto de sua liderança econômica quanto da liderança tecnológica, bem como da intensa massificação do ensino superior no país, fenômeno que precedeu o que posteriormente ocorreria na Europa.

Numa sociedade moderna com altos níveis de tecnologia e de informação, se torna imperativo a busca do conhecimento, e as capacitações em nível superior, especialmente no segmento da pós-graduação stricto sensu tem sido o elo entre a ciência, a pesquisa, a inovação, o aprofundamento nas questões das transformações sociais, do incremento empreendedorista no setor econômico e principalmente, o tecnológico.

Moritiz et al. (2013) enfatiza que mesmo com grandes conquistas, há muito pouco investimento nas estruturas exigidas pelos cursos de pós-graduação nas 
universidades brasileiras; falta ainda: políticas de governo com mais ênfase na altura da valorização da pesquisa; necessidades de ampliação na internacionalização e intercâmbios educativo-culturais; e, estanques sobre as diferenças regionais presentes no processo legislativo de reconhecimento de titulação de universidades do exterior, em especial atenção da América Latina.

Observa-se ainda que as ofertas de cursos de pós-graduação no ensino superior no Brasil enfrentaram e enfrentam diversos problemas que vem como herança de governo a governo, deixando de lado investimentos na pesquisa e em pesquisadores, não acompanhando as grandes transformações sociais, políticas e econômicas que refletem um novo contexto na sociedade brasileira, principalmente, no mundo acadêmico no ensino superior.

Também cabe ressaltar que com o advento de parcerias e intercâmbios culturais, principalmente, em nível de Mercosul, os cursos e programas de pós-graduação de mestrado e doutorado tomou grande vulto, seja pela questão geográfica, pela facilidade ofertada pelos pares, custos acessíveis e por facilidades em relação ao tempo de realização dos respectivos cursos.

Dessa forma, entende-se que a pós-graduação nos dias atuais tornou-se um caminho necessário para o desenvolvimento de capacitação nos setores da pesquisa científica e dos recursos humanos para o incremento de novos profissionais no ensino superior com maior qualificação de conhecimentos em áreas específicas.

A delimitação de estudo será no campo do curso de pós-graduação stricto sensu (mestrado) realizado no exterior e com finalidade específica de explorar as questões legais para validação/revalidação e reconhecimento de diplomas.

Portanto, ao partir da premissa da estruturação histórica da pós-graduação, objetivase tratar de forma conceitual a legislação brasileira sobre cursos stricto sensu realizados fora do país. Tendo como foco de objetivos específicos as perspectivas de conceituar cursos stricto sensu; e, tratar sobre a legislação brasileira nos cursos stricto sensu realizados fora do Brasil. 
Lakatos e Markoni (2015, p. 15) enfatizam que: "Pesquisar não é apenas procurar a verdade; é encontrar respostas para questões propostas, utilizando métodos científicos".

Desta forma, pode considerar-se que a pesquisa é um instrumento amplo e complexo necessitando de um planejamento ordenado para sua realização.

De acordo com Gil (2017) a pesquisa exploratória está embasada na construção de hipóteses que estão correlatas ao objeto de estudo escolhido. Aliando-se, portanto, as teorias dos métodos de pesquisa, elegeu-se a pesquisa bibliográfica, no sentido de coletar informações em artigos científicos, publicações de teses e dissertações, revistas eletrônicas e obras que possam enriquecer o rol de dados inerentes ao tema nomeado.

Portanto, pretende-se argumentar a descrição redacional deste estudo de natureza qualitativa, na coleta de informações teóricas que tratam exclusivamente sobre o tema proposto.

\section{MODALIDADES DAS PÓS-GRADUAÇÕES}

A pós-graduação lato sensu e a stricto sensu no Brasil se deu através do Parecer № 977/1965, conceituando e definindo os programas de cursos em nível de aperfeiçoamento e especialização. A Stricto Sensu é apresentada como um "[...] sistema de cursos que se superpõe à graduação com objetivos mais amplos e aprofundados de formação científica ou cultural." (LIEVORE, PICININ e PILATTI, 2017, p. 208).

Rego e Mucci Junior (2015, p. 147) fazem menção distinguindo que: "[...] 'stricto sensu' dirigida para aqueles interessados na carreira acadêmica, na versão 'lato sensu' está voltada para quem deseja ater em atividades profissionais e trabalhar em organizações de cunho produtivo científico, cultural, tecnológico". (Grifos dos autores).

Em termos específicos as modalidades de pós-graduação são divididas em dois tipos: a) Stricto Sensu focado na produção de pesquisas para obter conhecimentos na 
perspectiva de gerar novos conhecimentos; necessitando de maior dedicação e tempo dos profissionais onde seus estudos resultarão em dissertações ou teses; duração em média de dois anos; b) Lato Sensu sugeridos para profissionais que carecem de ampliação de conhecimentos específicos mais céleres, em torno de um a um ano e meio de duração (ou menos); normalmente são procuradas por profissionais já graduados e querem dar continuidade em sua formação e capacitação, estando ou não atuando profissionalmente. (CERETTA, 2013).

Kepler (2017) igualmente corrobora citando que em relação ao Mestrado há duas conjunturas distintas: a) Mestrado Acadêmico com evidência na investigação acadêmica entranhar-se em conhecimentos de temas que possam contribuir de forma relevante para a comunidade escolar e/ou a sociedade; trata-se de uma preparação para o desenvolvimento de habilidades didático-pedagógicas; b) Mestrado Profissional com ênfase a pesquisa científica, partindo de alguma hipótese, testes comparativos e de resultados já desenvolvidos, investir em inovações científicas que poderão contribuir o desenvolvimento de tecnologias, serviços, produtos, meio ambiente, empreendedorismo, entre outros.

Para Oliveira e Brotto (2018, p. 197): "A fundamental diferença entre o Mestrado Acadêmico e o Mestrado Profissional é o resultado final".

\subsection{PÓS-GRADUAÇÃO STRICTO SENSU}

Pode definir-se pós-graduação Stricto Sensu em um programa de formação intelectual e à produção do conhecimento por meio de pesquisa científica, atividades de ensino e extensão, visando ao aprofundamento dos conhecimentos acadêmicos e técnicoprofissionais, em campos específicos do saber. (AGUIAR NETO, 2014).

Santos (2015) faz uma menção histórica ao citar que através do Parecer 977 do Conselho Federal de Educação (CFE) no ano de 1965 foi criado o sistema brasileiro de pós-graduação stricto sensu e que recebeu o codinome de Parecer Newton Sicupira. 
Santos (2015, p. 9) expõe que:

A pós-graduação stricto sensu foi reconhecidamente como um novo coeficiente de ensino mais a frente da graduação, cujo escopo é ampliar e aprofundar a gênese educacional contraída na esfera dessa e propiciar o alcance de grau acadêmico superior [...] São distinguidos dois estágios na pós-graduação stricto sensu do Brasil: o mestrado e o doutorado.

Cirani, Campanario e Silva (2015) comentam que a pós-graduação stricto sensu no Brasil ocorreu junto com a concepção da CAPES, em meado de 1951, como instituição alistada ao Ministério da Educação cuja finalidade é dar cumprimento à política nacional de pós-graduação.

Os autores acima citados ainda apontam a existência de diversos graus de dificuldades no segmento da pós-graduação brasileira em termos estruturais e de investimentos, levando-se em conta a demanda de necessidade de qualificação de pessoal em todas as áreas possíveis do conhecimento em nível superior.

A sistematização da pós-graduação stricto sensu tem como foco a geração do conhecimento, destinados à formação e capacitação mais ordenada de professores do nível superior, pesquisadores e profissionais com dilatada propriedade em algum campo específico do saber, observando sua capacidade de liderança e inovação. Os citados cursos estão delineados e caracterizados em áreas de concentração, linhas de pesquisa, disciplinas. São orientados por profissionais gabaritados e capacitados para tal, de forma individual. "A pós-graduação é um sistema de formação intelectual e, ao mesmo tempo, de produção de conhecimento nas respectivas áreas do saber." (UDESC, 2017, p. 10).

Para Takahashi et al. (2010), os desafios mais frequentes nos programas de mestrado pós-graduação stricto sensu no Brasil estão nas questões teóricas, legais, normativos, e, práticos. Takahashi et al. (2010) explana que por teóricos está na clareza do conceito da finalidade, do pressuposto e das características de cada um dos programas; em termos legais e normativos subentende-se a regulamentação clara sobre o papel de cada programa e suas diferenças perante as instituições ofertantes para que possam optar pelo(s) curso(s) ofertado(s) e que possam ter ciência sobre os 
critérios de proposta e avaliação; e por práticos refere-se ao conhecimento e à interpretação de cada instituição de ensino sobre o conceito e a legislação que define cada tipo de curso na estrutura de pós-graduação stricto sensu.

O mestrado acadêmico tem como fundamentação a motivação do discente à pesquisa, de forma gradual, que o preparará para a realização de produções independentes de trabalhos científicos, através dos variados tipos de materiais como artigos científicos, revistas físicas e eletrônicas especializadas na área afim, anais de congressos, entre outros. Desta forma, "[...] é exigido do discente, dedicação, foco e muita pesquisa de forma que seu potencial redacional atinja certo grau de qualidade na construção textual de elementos científicos, compreensíveis e de forma metodológica." (REGO e MUCCI JUNIOR, 2015, p. 161).

\subsection{BREVE HISTÓRICO DA INSTITUIÇÃO BRASILEIRA DE PÓS- GRADUAÇÃO}

Conforme Melo (2012), foi o parecer n 977/65 que definiu as normas gerais de pósgraduação no Brasil. Esse documento definiu a pós-graduação como componente de um sistema de ensino que ficaria sistematizado em Stricto Sensu (mestrado e doutorado); Lato Sensu (aperfeiçoamento e especialização). No entanto, por volta de 1990 iniciou-se um debate para que emanasse uma nova conceituação em relação à modalidade Stricto Sensu, para que se evidenciassem considerações diferenciadas dos cursos contemporâneos sobre o mestrado acadêmico, colimando na LDB no 9.394/1996.

Por meio da resolução ํㅜ 7/17, do Ministério da Educação, ficou estabelecido que na referência de mestrado e doutorado nos programas de pós-graduação stricto sensu, deverão sistematicamente e de contorno crível serem avaliados pela Coordenação de Aperfeiçoamento de Pessoal de Nível Superior (CAPES). (BRASIL, 2017).

Desta forma, o Art. $1^{\circ}$ da Resolução $7 / 17$, em seu $\S 1^{\circ}$ propõe que mestrado e doutorado deverão ser direcionados para a produção intelectual com o compromisso de avanços em diversas áreas da sociedade. No $\S 2^{\circ}$ está estabelecido que mestrado 
e doutorado se diferenciem no contexto da duração do programa, de sua complexidade curricular, a característica do trabalho final após conclusão de curso. No $\S 3^{\circ}$ considera que ao cursar o mestrado, essa titulação não estabelece condição imperativa para ingressar em programa de doutorado e em seu $\S 4^{\circ}$ está redacionado que a língua estrangeira será parte integrante de atividades dos programas tanto de mestrado como de doutorado, inclusive nas apresentações e defesas de teses, dissertações ou outros instrumentos de finalização de curso. (BRASIL, 2017).

Ainda no disposto do $\S 2^{\circ}$. Art. $2^{\circ}$. Resolução $7 / 17$, que é uma das funções da CAPES a definição dos métodos que deverão compor o rol avaliativo dos cursos de mestrado e doutorado profissionais. Em seu Art. 3ํㅡ $\S 1^{\circ}$ do art., Res. 7/17 e com complementação da Portaria Normativa 11/2017/MEC, onde estão determinadas quais as modalidades presenciais poderão ser ministradas pela instituição de ensino superior, tais como: polos de educação à distância ou em ambiente profissional e que atendam os ditames legais e normais regimentais da pós-graduação stricto sensu. (BRASIL, 2017).

Silva et al (2016) apontam que a pós-graduação stricto sensu no Brasil é atualmente organizada em nove principais áreas, sendo: ciências exatas e da terra, ciências biológicas, ciências da saúde, ciências agrárias, engenharias, multidisciplinar, ciências humanas, ciências sociais aplicadas e linguística, e letras e artes.

Entretanto, o ingresso formal nos programas de mestrado e doutorado estão enfaticamente sujeitos às determinadas vindicações da instituição ofertante, podendo sim ou não criar e estabelecer critérios limitadores de acesso.

\subsection{MESTRADO STRICTO SENSU NO EXTERIOR}

Sobre as vantagens de realizar um curso stricto sensu fora do Brasil, Passos (2009) comenta que é fundamental enfatizar que diversos cursos de pós-graduação são excepcionais em instituições brasileiras e, em determinadas áreas de estudo, não deixam nada a desejar a programas acadêmicos internacionais. 
Conforme a autora, caso seja um candidato de mestrado, não existe uma razão essencial para sair do país. Isso porque a maior parte dos cursos de mestrado no Brasil é bem avaliada pela Capes, sendo melhores do que cursos denominados de "mestrado" que são ofertados no exterior.

Nas explicações de Mazzuoli (2010) nas questões sobre o embasamento jurídico das titulações dos programas de mestrado e doutorado cursados no exterior, em primeiro plano de seu estudo está na composição dos países parceiros do Mercosul.

O autor prossegue dizendo que entre os Estados-membro do Mercosul, através do Decreto no $5.518 / 2005$ foi firmado um acordo para que se admitisse títulos e graus universitários, propiciando dessa forma, um maior espaço para que interessados pudessem nesse intercâmbio ingressar cursos de pós-graduação stricto sensu, dentro do quadrante do universo dos países membros desta congregação de países do bloco do Mercosul.

Todavia, ressalta Mazzuoli (2010), que mesmo com o referido acordo, não significa que está deliberado a um brasileiro ao obter um título de mestre ou doutor em países estrangeiros terá automaticamente direito de exercer os direitos lhes conferidos nas titulações em utilizá-los automaticamente no território brasileiro. Após a conclusão dos estudos, o indivíduo terá que necessariamente revalidar seu título nos termos da LDB no 9.394/1996, e de conformidade com as demais legislações e resoluções em vigor na esfera educacional brasileira notadamente no ambiente universitário.

Assim, o autor observa que o mencionado acordo apenas facilita a parceria acadêmica dentre as instituições de ensino superior dos países considerados interculturalizados em programas específicos no intuito de melhorar o aperfeiçoamento e da capacitação nas esferas da ciência, tecnologia e da cultura geral, bem como a modernização dos Estados partes, mas não dispõe sobre os brasileiros que obtém seus títulos nesses Estados exteriores e que pretendem exercer, em seu país de origem, os direitos conferidos por esse título. 
Sendo assim, Mazzuoli (2010) explica que qualquer brasileiro que cursa pósgraduação stricto sensu fora do país - em Estados-membro do Mercosul ou não -

deverá atender o que expressa o Art. 4ํำ da Resolução CNE/CES ํㅜ 1/01 onde está expresso que para reconhecimento oficial brasileiro é imprescindível que os respectivos diplomas devam ser reconhecidos, validos e registrados pelas instituições educacionais de ensino superior brasileira, respeitando nível equivalente ou em nível superior e ainda, especificidade de áreas afins.

\subsection{PRINCIPAIS LEIS BRASILEIRAS QUE REGEM OS CURSOS STRICTO SENSU REALIZADOS NO EXTERIOR}

Ao se tratar de legislação brasileira em recepcionar diplomas de mestrado Stricto Sensu no exterior, ao longo dos anos foram sendo implementadas diversas leis e regulamentações, de acordo com a contextualização temporal e das necessidades internas da educação nacional.

De forma resumida a legislação brasileira se dá nas seguintes condicionantes:

- Art. 48 da Lei oㅜ 9.394/1996, parágrafo 3o - Aborda a revalidação de diplomas de mestrado e doutorado expedidos por Universidades estrangeiras;

- Resolução no 1/2001-CNE/CES de 03/04/2001, Artigo 4 - versa sobre a revalidação nacional por cursos de pós-graduação autorizados pela CAPES, de diplomas de mestrado e doutorado expedidos por Universidades estrangeiras;

- Resolução № 3 de 22/06/2016, Capítulo III do CNE - propõe normas alusivas ao reconhecimento de diplomas de pós-graduação stricto sensu (mestrado e doutorado), emitidos por instituições estrangeiras de ensino superior;

- Portaria Normativa № 22 de 13/12/2016/MEC., Capítulo IV - regulamenta os procedimentos gerais de tramitação de processos de solicitação de revalidação de diplomas de graduação estrangeiros e ao reconhecimento de diplomas de pós- 
graduação stricto sensu (mestrado e doutorado), emitidos por instituições estrangeiras de ensino superior (OLIVEIRA, 2017).

Segundo Silva e Porciúncula (2017) com as inovações e modernidades atuais os órgãos da educação brasileira acompanham em aplicações de diversas políticas para a formação acadêmica de profissionais em nível de ensino superior, como é o caso da implantação da Lei oㅜ 13.005 de 25/06/2014 que prevê formação continuada constantes no Plano Nacional de Educação/PNE para o decênio 2011/2020.

O EaD toma ponto de destaque no plano de modernização do MEC em relação a inovações que regulamentam programas de pós-graduação stricto sensu à distância, que está divulgado no Portal da CAPES (2018) onde a partir de então, os estabelecimentos de ensino superior terão condições de ofertar cursos stricto sensu à distância, equivalentes a mestrado/doutorado acadêmico no contexto acadêmico e/ou profissional. Também trata dos currículos onde devem constar estudos de forma presencial, grade de estágios obrigatórios, congressos, seminários, simpósios integrativos, práticas de laboratório, entre outras. Esses cursos serão regularmente avaliados e monitorados por comissões de especialistas em EaD, para eventual irregularidades e desqualificação nas condições científicas necessárias para o excelente desempenho do campo do conhecimento e da pesquisa.

Os referidos ditames da legislação brasileira deve ser subentendido aquelas instituições que possuem em sua grade de programas de cursos de pós-graduação devidamente registrados, legalizados e avaliados pela CAPES. Tendo como critério fundamental que cursos do exterior tenham equivalência na mesma área de ciência e em grau análogo ou superior. (CAPES, 2017).

Através da Portaria ํㅡ 80/98, a CAPES depois de muitos embates e deliberações, finalmente, reconheceu o mestrado profissionalizante, e que tinha como princípio não formar pesquisadores, como os mestrados e doutorados acadêmicos. Partindo dessa premissa, o mestrado profissional teve sua caracterização independente e distinta na sua estrutura curricular e especificidade, propondo a essência do conhecimento na aplicabilidade da prática profissional. 
É fato sine qua non que o estudante para obter e usufruir de forma oficial de seu certificado auferido em instituições estrangeiras, deverá fundamentalmente atender todas as demandas documentais e legislativas estabelecidas no Art. 18 da Resolução $3 / 16$, sendo vedado peremptoriamente reconhecimento ou validação por mais de uma universidade em nível de ensino superior. (CAPES, 2017).

Também é citada por Novo (2018) que o MEC, com a pretensão de acelerar os procedimentos na tramitação de processos de revalidação/reconhecimento de diplomas do exterior no Brasil, criaram a Plataforma Carolina Bori (14/07/2017), essa ação dinamizou a revalidação e a condição de reconhecimento de diplomas obtidos no exterior justamente por existir uma lacuna jurídica no contexto da Política de Internacionalização do Ensino Superior.

Cabe ressaltar que a CAPES além de todo processo de avaliação e acompanhamento de qualificação das instituições em nível superior, atua também, de forma efetiva na esfera institucional em acompanhar e abalizar o acesso à publicação da produção científica, investimento na formação de alto nível na educação brasileira e no exterior e no agenciamento da cooperação científica internacional. Já, numa outra perspectiva, está a esfera social que é agenciar e facilitar a divulgação e do acesso da informação produzida no meio acadêmico, apresentando serviços como Banco de Teses, Plataforma Lattes, Portal de Periódicos, Plataforma Carlos Chagas, além de vários programas de concessão de bolsas de estudos. Objetivando qualificar e certificar os programas de pós-graduação do país, a CAPES, a cada quatro anos, realiza avaliações em cursos de mestrado, mestrado profissional e doutorado de todo o país. (MACÊDO org., 2017).

Amorin (2016) salienta que na legislação brasileira a revalidação de diplomas em nível de graduação está sob a jurisdição das universidades públicas, sendo que em relação a diplomas de mestrado e/ou doutorado stricto sensu também poderá ser validado por instituições particulares.

Em relação aos processos de revalidação e reconhecimento já protocolados junto às universidades, deverá ser respeitado o prazo máximo de noventa dias. Os que tiverem 
processos de revalidação ou reconhecimento em andamento podem optar por um novo protocolo que esteja de acordo com os termos da resolução, o prazo para isso é de trinta dias. (CAPES, 2017).

Outro ponto a destacar em relação à validação de diplomas no exterior, na descrição de Amaral (2017) é que desde 2016, o Brasil adotou a aplicação da Convenção da Apostila de Haia como fonte de integração para simplificação e legalização documental entre membros de 112 nações, adeptas desse tratado, favorecendo o reconhecimento de documentação de brasileiros no exterior e vice-versa.

Também é citado por Amaral (2017) sobre o Portal Carolina Bori (Portaria no 022/2016) como um instrumento de auxílio para discentes validar e revalidar seus diplomas de graduação e/ou pós-graduação com emissão no exterior. Neste portal Carolina Bori, o interessado acessa e lá estará o rol de universidades autorizadas e legalizadas, número de vagas disponíveis nas instituições afins, os processos em andamento para validações e/ou revalidações. Importante destaque que a autora ressalta é que para reconhecimento de diplomas em nível de graduação sempre será realizada por instituições públicas e diplomas relacionados a mestrado ou doutorado stricto sensu poderão ser realizado tanto por instituições públicas como também de instituições privadas. (AMARAL, 2017).

Outro ponto de destaque é que fica estabelecido o prazo máximo de 180 (cento e oitenta) dias para que as instituições consideradas legais para validação de diplomas avaliem os respectivos processos.

\section{CONSIDERAÇÕES FINAIS}

Ao analisar este breve estudo bibliográfico, pode-se observar inicialmente que todos os programas de cursos de pós-graduação tanto lato sensu como stricto sensu que compõem o conjunto de mestrado e doutorado são todos regulados e avaliados pela CAPES, tanto em nível nacional como validações de diplomas realizados em cursos no exterior. 
Observou-se também que o Brasil caminha a passos largos para aproximar-se na esfera educacional de países mais adiantados do segmento de pós-graduação lato sensu e stricto sensu (Mestrado e Doutorado), com inclusão no programa de educação à distância para que haja um salto qualitativo no aperfeiçoamento, capacitação e desenvolvimento da produção acadêmica tanto em nível educacional, tecnológico, científico e cultural.

Como foco central deste estudo, verificou-se que não há impedimento na legislação brasileira em cursar pós-graduação seja no segmento de mestrado ou doutorado no exterior, entretanto, cabe ao interessado saber se na instituição estrangeira escolhida está em alinhamento com a legislação educacional brasileira.

Foram pontos fundamentais observados que na hora da validação e/ou revalidação do diploma obtido na instituição estrangeira, é de extrema relevância a atenção do discente em pesquisar se ela propõe áreas de concentração, linhas de pesquisa, disciplinas que estejam de acordo com a oferta e estão contempladas nas universidades brasileiras, regularmente autorizadas pela CAPES. Se a temporalidade do curso, se a programação curricular está dentro dos parâmetros exigidos pela legislação brasileira, entre outras.

Portanto, estas questões são basilares para os discentes que procuram especialização em pós-graduação stricto sensu no exterior.

Também são observáveis que na condição de cursar no exterior, existem na legislação brasileira as parcerias internacionais que se consolidam com exclusiva finalidade do compartilhamento intercambial de nível educacional.

Isso denota, legalmente, que os diplomas auferidos por estudantes brasileiros no exterior, estarão necessariamente sujeitos a submeter-se a um processo de revalidação em universidades brasileiras. De forma que sua aceitação ou não, fica a critério das pró-reitorias das universidades nacionais, sendo o aceite ou recusa do título inquestionável, já que esses órgãos possuem força de normativa interna nas instituições de ensino superior. 
Significa que o reconhecimento oficial de validação ou reconhecimento diplomas de mestrado ou doutorado obtidos no estrangeiro somente se dará se a instituição brasileira esteja regularmente credenciada pela CAPES e que constem nos seus programas de pós-graduação de mestrado ou doutorado, cursos da mesma área de conhecimento do título a ser revalidado.

Ou seja, ainda que existam acordos e a possibilidade de realizar cursos stricto sensu em universidades do exterior, existe um processo burocrático-legal a ser enfrentado pelo brasileiro que desejar fazer uso do seu título de mestre e doutor no Brasil. Dessa forma, constata-se que as facilidades oferecidas para a realização de intercâmbios, tendem a se limitar ao campo acadêmico, à experiência empírica e que, serão burocráticos para revalidar o título e permitir que o indivíduo usufrua de seus benefícios dentro de seu próprio país.

Desta forma, considera-se que os objetivos previamente previstos foram atendidos, mesmo com certa dificuldade de material bibliográfico específico, e os problemas levantados foram atendidos para enriquecimento informativo do presente. Considerase ainda que não é intenção de se esgotar o tema, mas sim, foi intento colaborar de forma simplista de apresentar alguns dados relevantes sobre o assunto de vulto e de vital importância nos meios acadêmicos atuais.

\section{REFERÊNCIAS}

AGUIAR NETO, Benedito Guimarães. Regulamento Geral da Pós-Graduação Stricto Sensu. Universidade Presbiteriana Mackenzie. Campus Higienópolis. São Paulo/SP. 2014. Disponível em: https://www.mackenzie.br/fileadmin/user_upload/upm_RE_CONSU_18_2014_Regul amentoGeral_Pos_graduacao_Stricto_Sensu_REG_Assinada.pdf. Acesso em: 10/04/2019.

AMARAL, Bruna Passos. Artigo. Partiu Intercâmbio/Estudar Fora. Estudarfora.org. 2017. Disponível em: <https://www.estudarfora.org.br/validacao-do-diplomaexterior/>. Acesso em: 10/04/2019. 
AMORIM, Rovênia. Novas regras vão facilitar a validação de diplomas emitidos por instituições do exterior. MEC/Educação Superior. 2016. Disponível em: $<$ http://portal.mec.gov.br/busca-geral/212-noticias/educacao-superior1690610854/43071-novas-regras-vao-facilitar-a-validacao-de-diplomas-emitidos-porinstituicoes-do-exterior>. Acesso em: 10/04/2019.

BRASIL. Parecer no 977/1965. Definição dos Cursos de Pós-Graduação. Disponível em: $<$ https://www.capes.gov.br/images/stories/download/legislacao/Parecer_CESU_977 1965.pdf>.

. Ministério da Educação. Conselho Nacional de Educação. Portaria Normativa no 22, de 13 de dezembro de 2016. Normas e procedimentos gerais de revalidação de diplomas de graduação estrangeiro e ao reconhecimento de pós-graduação stricto sensu (mestrado e doutorado), expedidos por estabelecimentos estrangeiros de ensino superior. Brasília: Diário Oficial da União, p. 9 a 11, seção 1, 14/12/2016. Disponível em: $<$ http://carolinabori.mec.gov.br/arquivos/Portaria_Normativa_n_22_de_13.12.2016. pdf>. Acesso em: 10/04/2019.

. Ministério da Educação. Conselho Nacional de Educação. Resolução no 7, de 11 de dezembro de 2017. Estabelece normas para o funcionamento de cursos de pós-graduação stricto sensu. Brasília: Diário Oficial da União, № 237, seção 1 , 12 dez. 2017, p. 21.

CAPES. Resolução do CNE estabelece normas para revalidação de diplomas obtidos no exterior. Jul. 2017. Disponível em: <http://www.capes.gov.br/36noticias/7954-resolucao-do-cne-altera-processo-de-reconhecimento-e-revalidacaode-diplomas-obtidos-no-exterior>. Acesso em: 10/04/ 2019.

CAPES. Regulamentação de pós-graduação Stricto Sensu à distância. Fundação Capes. Sala de Imprensa. 20/12/2018. Disponível em: <http://www.capes.gov.br/sala- 
de-imprensa/noticias/9279-regulamentacao-de-pos-graduacao-stricto-sensu-adistancia>. Acesso em: 10/04/2019.

CERETTA, Carlos Alberto. Entenda a diferença entre as modalidades de lato sensu e stricto sensu. Universidade Federal de Santa Maria/RS. Disponível em: https://gauchazh.clicrbs.com.br/geral/noticia/2013/04/entenda-a-diferenca-entre-asmodalidades-de-lato-sensu-e-stricto-sensu-4107813.html. Acesso em: 10/04/2019.

CIRANI, Cláudia Brito Silva; CAMPANARIO, Milton de Abreu; SILVA, Heloísa Helena Marques da. A evolução do ensino da pós-graduação senso estrito no Brasil: análise exploratória e proposições para pesquisa. Avaliação, Campinas; Sorocaba, SP, v. 20, n. 1, p. 163-187, mar. 2015. Disponível em: $<$ http://www.scielo.br/pdf/aval/v20n1/1414-4077-aval-20-01-00163.pdf>. Acesso em: 10/04/2019.

GIL, A. C. Como elaborar projetos de pesquisa. 5. ed. São Paulo: Atlas, 2017.

KEPLER, Yuri. Saiba quais são as diferenças entre mestrado acadêmico e profissional. Universidade Tuiuti do Paraná. 2017. Disponível em: < https://www.tuiuti.edu.br/blog-tuiuti/saiba-quais-sao-as-diferencas-entre-mestradoacademico-e-profissional>. Acesso em: 10/04/2019.

LAKATOS, E. M.; MARCONI, M. A. Técnicas de pesquisa: planejamento e execução de pesquisas, amostragens e técnicas de pesquisas, elaboração, análise e interpretação de dados. São Paulo: Atlas, 2015.

LIEVORE, Caroline; PICININ, Claudia Tania; PILATTI, Luiz Alberto. As áreas do conhecimento na pós-graduação stricto sensu brasileira: crescimento longitudinal entre 1995 e 2014. Ensaio: aval. pol. públ. Educ., Rio de Janeiro, v.25, n. 94, p. 207237, jan./mar. 2017. Disponível em: http://www.scielo.br/pdf/ensaio/v25n94/18094465-ensaio-25-94-0207.pdf. Acesso em: 10/04/2019.

MACÊDO, Maria Ayrlles (org). Interdisciplinaridade e programas de pósgraduação no Brasil. IV Congresso Nacional de Educação/CONEDU. Universidade 
Federal

do

Cariri/UFCA.

2017.

Disponível

em:

<https://editorarealize.com.br/revistas/conedu/trabalhos/TRABALHO_EV073_MD1_S A2_ID7214_17102017115035.pdf>. Acessso em: 10/04/2019.

MAZZUOLI, Valério de Oliveira. A questão do reconhecimento de títulos de mestrado e doutorado provenientes dos países do Mercosul. Agenda Social. V.4, n³, set-dez / 2010, p. 20-37. Disponível em: <https://www.revistas.ufg.br/revfd/article/view/15585/9539.. Acesso em: 10/04/2019.

MELO, K. V. A. Origem e institucionalização da pós-graduação stricto sensu profissional: um estudo de casos. Recife: UFPE, 2012. (Dissertação de mestrado). Disponível

em: $<$ https://repositorio.ufpe.br/bitstream/123456789/1175/1/arquivo1738_1.pdf>. Acesso em: 10/04/2019.

MORITZ, Gilberto de Oliveira et al. A pós-graduação brasileira: evolução e principais desafios no ambiente de cenários prospectivos. Future Studies Research. 5. São Paulo, v.5, n.2, pp. 03 - 34, Jul./Dez. 2013. Disponível em: <https://revistafuture.org/FSRJ/article/download/136/227>. Acesso em: 10/04/2019.

NOVO, Benigno Núnez. O reconhecimento de títulos de pós-graduação do exterior no Brasil. 2018.2 Disponível em: <https://benignonovonovo.jusbrasil.com.br/artigos/649752282/o-reconhecimento-detitulos-de-pos-graduacao-do-exterior-no-brasil?ref=serp>. Acesso em: 10/04/2019.

OLIVEIRA, Sâmela Soraya Gomes de. Procedimento para reconhecimento de diplomas de Cursos de Pós-Graduação Stricto Sensu expedidos por estabelecimentos estrangeiros de Ensino Superior. Universidade Potiguar. Natal/RN. 2017. Disponível em: https://unp.br/wpcontent/uploads/2016/09/Revalida\%C3\%A7\%C3\%A3o-de-diplomasestrangeiros.pdf. Acesso em: 10/04/2019.

OLIVEIRA, David Mesquiati de; BROTTO, Júlio Cezar de Paula. O trabalho de Conclusão de Curso (TCC) no Mestrado Profissional (MP): um estudo de caso do 
MP em Ciências das Religiões da Faculdade Unida. Estudos de Religião, v. 32, n. 1, 191-210, jan/abr. 2017. Disponível em: https://www.metodista.br/revistas/revistasims/index.php/ER/article/viewFile/7504/6233. Acesso em: 10/04/2019.

PASSOS, Maria do Carmo Friche. Pós-graduação no exterior: vale a pena? Arq Gastroenterol, v. 46, n. 1, jan./mar. 2009. Disponível em: $<$ https://www.researchgate.net/publication/250022359_Posgraduacao_no_exterior_vale_a_pena>. Acesso em: 10/04/2019

REGO, Ihgor Jean; MUCCI JÚNIOR, Luiz Carlos. Pós-Graduação Lato Senso e Stricto Senso: Direito fundamental à educação capaz de conduzir a um relevante e renovado inovador Brasil do futuro. Revista dos Direitos Sociais e Políticas Públicas (UNIFAFIBE). vol. $\quad 3, \quad$ n. $\quad 1, \quad 2015 . \quad$ Disponível em: $<$ http://www.unifafibe.com.br/revista/index.php/direitos-sociais-politicaspub/article/view/68/pdf_37>. Acesso em: 10/04/2019.

SANTOS, Anelise Schaurich dos. $\mathbf{O}$ ingresso no Mestrado e a adaptação à pósgraduação Stricto Sensu. Dissertação de Mestrado. Universidade Federal de Santa Maria-UFSM. Santa Maria/RS. 2015. Disponível em: <https://repositorio.ufsm.br/bitstream/handle/1/10342/SANTOS\%2C\%20ANELISE\%2 OSCHAURICH\%20DOS.pdf? sequence=1\&isAllowed=y . Acesso em: 10/04/2019.

SILVA, Lidiane Cristina et al. Panorama dos programas de pós-graduação stricto sensu em gestão do conhecimento no Brasil. In: XIII Simpósio de Excelência em Gestão e Tecnologia - SEGeT. Out. 2016. Disponível em: $<$ https://www.aedb.br/seget/arquivos/artigos17/25925350.pdf>. Acesso em: 10/04/2019.

SILVA, Vidiane Casimiro da; PORCIÚNCULA, Lisiane de Oliveira. Impactos da pósgraduação stricto sensu na formação de professores de português da educação básica do Distrito Federal. Revista Brasiliera de Pesquisa sobre Formação Docente. Form. Doc., Belo Horizonte, v. 09, n. 17, p. 141-162, ago./dez. 2017. Disponível em: 
<https://www.revformacaodocente.com.br/index.php/rbpfp/article/view/156/144>. Acesso em: 10/04/2019.

TAKAHASHI, Adriana Roseli Wunsch et al. Mestrado Profissional e Mestrado Acadêmico: Convergências, Divergências e Desafios aos programas de PósGraduação Stricto Sensu no Brasil. EnEPQ. 2010. Disponível em: <https://raep.emnuvens.com.br/raep/article/view/129/70>. Acesso em: 10/04/2019.

UDESC/Universidade do Estado de Santa Catarina. Guia do aluno de Mestrado e Doutorado. Florianópolis/SC. 2017. Disponível em: <https://www.udesc.br/arquivos/udesc/documentos/0_56391900_1474299423.pdf>. Acesso em: 10/04/2019.

Enviado: Junho, 2019.

Aprovado: Dezembro, 2019. 